Institute for Empirical Research in Economics

University of Zurich

Working Paper Series

ISSN 1424-0459

Working Paper No. 519

\title{
Per-Capita Incomes and the Extensive Margin of Bilateral Trade
}

Christian Hepenstrick

November 2010 


\title{
Per-Capita Incomes and the Extensive Margin
}

\section{of Bilateral Trade*}

\author{
Christian Hepenstrick ${ }^{\dagger}$
}

November 18, 2010

\begin{abstract}
This paper argues that the per-capita income of importers is an important determinant of the extensive margin of trade. I formalize this by incorporating preferences that allow for binding nonnegativity constraints into an otherwise standard Ricardian model. This implies that agents adjust the set of goods from which they consume with income, which in turn affects the extensive margin of bilateral trade. I quantify the model using data on US consumer behavior and aggregate values of bilateral trade flows. I find that the behavior of the model's extensive margin of bilateral trade is consistent with elasticities measured in the data. Two counterfactual experiments demonstrate the quantitative importance of the mechanism outlined in this paper.
\end{abstract}

\footnotetext{
*I thank Ana Cecília Fieler, Kevin Staub, Gino Gancia, Pedro Mira, Josef Zweimüller, Alessandro Barattieri, Marc Melitz, Pol Antàs, Tomasz Swiecki, Elhanan Helpman and seminar participants at University of Zurich, the Vienna Institute for International Economic Studies, Harvard University, and EconCon for helpful comments and discussions. I gratefully acknowledge financial support by the Verein zur Förderung des Akademischen Nachwuches, the Ecosciencia Foundation, and the Swiss National Science Foundation.

${ }^{\dagger}$ University of Zurich, Institute for Empirical Research in Economics, Mühlebachstrasse 86, CH-8008 Zürich, hepenstrick@iew.uzh.ch
} 


\section{Introduction}

Trade flows greatly vary in the number of different goods that are traded between countries. This "extensive margin of bilateral trade" can be thought of as the manifestation of an interplay of the exporter's production technology, the importer's demand structure, and bilateral trade costs - it is more likely that two countries trade a given good if the exporter is particularly strong in producing this good, the importer has a especially high demand for that good, or bilateral trade barriers are low. Most existing analyses of the extensive margin of bilateral trade focus on the exporter's technology and bilateral trade costs. This paper provides a complementary perspective by emphasizing the role of the importing country's demand structure.

For this purpose I adapt the Ricardian multi-country model by Eaton and Kortum (2002) (henceforth EK). In the EK framework the production technology is country-variety specific. Together with trade costs this determines the price at which a supplying country can offer a variety in a particular destination market. In any given destination market the producer country offering the lowest price will be the sole supplier of this variety. However, whether this trade flow then actually materializes depends not only on the supplier country's good technology and low bilateral trade costs, but crucially also on the importing country's demand structure - particularly on if at the price offered there is actually a positive demand for this variety. With the traditional CES preferences demand is always positive since the marginal utility is unbounded. In this paper I relax this assumption and allow agents to adjust the set of goods they purchase - henceforth called the "extensive margin of consumption" - with income. ${ }^{1}$ In choosing their optimal consumption bundle agents order the varieties along their prices and decide up to which price it is optimal to consume positive quantities. It therefore is possible that for a given variety the lowest price offered by the supplier countries is still too high and the agents in the importing country find it optimal not to consume (and therefore not to import) this variety. The corresponding model is developed in Section 2.

A thus extended model helps to make sense of the empirical behavior of the extensive margin of trade. It has been documented in several studies that richer countries both import and export more varieties (see e.g. Hummels and Klenow (2002), Baldwin and Harrigan (2007), or Sauré (2009)).

Table 1 summarizes these findings by regressing the extensive margin of bilateral trade in consumption

\footnotetext{
${ }^{1}$ Jackson (1984) documented the empirical relevance of the "extensive margin of consumption" using US consumer expenditure data. Falkinger and Zweimüller (1996) provide evidence that richer countries consume a broader set of goods using the Worldbank's ICP-data. Other studies documenting positive correlations between variety and income include Jekanowski and Binkley (2000), Moon, Florkowski, Beuchat, Resurreccion, Paraskova, Jordanov, and Chinnan (2002), Thiele and Weiss (2003), and Li (2010) for food consumption and Gronau and Hamermesh (2008) documenting similar effects in time use data.
} 
goods $^{2}$ on the per-capita incomes and population sizes of the trading partners (controlling for bilateral resistance).

Table 1

The positive elasticity of the exporter per-capita income can be understood as a standard Ricardian mechanism: per-capita income is high due to a country's good technology. But being technologically advanced implies that this country is competitive in many industries and therefore tends to export a broad set of varieties. However, at the same time this implies that the number of varieties that need to be imported is relatively low. Allowing for the extensive margin of consumption to adjust with income generates a countervailing force.

In order to assess whether this force is strong enough to dominate the negative effect coming from the supply side I quantify the model in Section 3. I use the aggregate values of bilateral trade flows to estimate the model's technologies and trade costs and data on US consumer expenditure to pin down the preference parameters. I then simulate the thus calibrated model and consider the behavior of its extensive margin of bilateral trade. I find that the demand side forces are sufficiently strong to dominate the negative effect of a good technology on the extensive margin of imports. Comparing the income elasticities of the extensive margin of bilateral trade to the data I find that they are of the right sign and close to the empirical elasticities.

What is the quantitative importance of this new demand side channel? To answer this question I use the calibrated model to perform two classical counterfactual experiments - lowering trade costs and the rise of China and India. A traditional model neglecting the demand side predicts that lower trade costs lead to higher extensive margins of trade since trade becomes worthwhile for more varieties. This effect is reinforced by the demand side. Lower trade cost lead to higher real incomes which induces agents to expand their extensive margins of consumption. This then increases the number of traded varieties. Quantitatively I find that the predicted increases in the extensive margins of bilateral trade flows are at least twice as high when allowing for the extensive margin of consumption to adjust. The second experiment considers the effect of technological progress in China and India. Better local technologies imply that these countries will tend to produce more varieties locally since they become more competitive. However, the rising incomes will lead consumers to expand the measure of varieties that they consume. This effect dominates and therefore the model with non-homothetic preferences

\footnotetext{
${ }^{2}$ I consider consumption goods only since the channel proposed in this paper affects the patterns of final demand only.
} 
predicts that the extensive margin of imports is rising, whereas a model neglecting demand side effects would actually predict falling extensive margins.

In this paper I use the EK framework since it is parsimonious in the context of my objective - it allows me to develop my argument in a very intuitive way and nevertheless provides me with a model that is general enough to be directly quantified. The message of the demand side being an important determinant of the extensive margin of trade however is more general. In Section 4 I discuss how the demand side effects would play in a model of monopolistic competition and heterogeneous firms and what additional effects and complications may emerge. Remaining in the Ricardian framework Section 5 discusses a number of extensions. First, I show that accounting for trade in intermediates does not significantly change the quantitative predictions of the model. Second, I consider the implications of allowing for within-country inequality, and third I show that the results are not driven by the particular functional form of the utility function. Section 6 concludes.

This paper contributes to two strands of the trade literature. First, by highlighting the role of the importer's demand structure it contributes to the broad literature investigating the extensive margin of trade. Second, on a more theoretical side it contributes to the growing literature that recognizes the potential importance of non-homothetic consumer behavior for understanding different aspect of trade pattern - aggregate values of trade flows, differences in unit prices, and the extensive margin of trade. ${ }^{3}$ As for the aggregate value of trade flows Fieler (2010) argues that non-homothetic preferences help to explain the higher trade share of rich countries. She extends the EK model to two industries with differing demand elasticities. Richer countries then relatively concentrate their expenditures in the high-elasticity industries. If the variability in productivities across countries is relatively high in these industries, their share of traded output will be high. Together with the demand pattern this implies that rich countries' trade shares are higher. With respect to the extensive margin of trade however, her model's predictions are similar to EK since agents do not adjust their extensive margin of consumption. Another aspect of trade pattern where non-homotheticity is potentially relevant is the variation in unit-prices across importing countries. Simonovska (2010) argues that differences in unit prices reflect differing markups due to demand elasticities that change with income. Choi, Hummels, and Xiang (2009) and Fajgelbaum, Grossman, and Helpman (2009) on the other hand understand differences in unit-prices as reflecting quality differences due to a increasing taste for quality with rising income. Concerning the extensive margin of trade Sauré (2009) argues that richer countries have

\footnotetext{
${ }^{3}$ For a more complete overview of the literature of non-homothetic preferences and trade see Markusen (2010).
} 
more trading partners (county level extensive margin) due to non-homothetic preferences and Foellmi, Hepenstrick, and Zweimüller (2010) show that non-homothetic preferences can generate incentives for parallel trade and influence the extensive margin of trade via this channel. This paper's contribution is a multi-country model of trade where the importing country's consumers decide about their extensive margin of consumption. This decision then determines together with the exporters technologies and the structure of trade costs the extensive margins of bilateral trade flows.

\section{A model of per-capita incomes and the extensive margin}

The world economy consists of $N$ countries. Country $i$ 's population is denoted by $L_{i}$. Each agent is endowed with one unit of labor that is inelastically supplied on the domestic market. There is one industry producing differentiated consumption goods. The measure of varieties is exogenous and normalized to one.

\subsection{Consumer behavior}

Agents maximize the same symmetric additively separable utility function

$$
U=\int_{0}^{1} v(x(j)) d j
$$

subject to their budget constraints $E \geq \int_{0}^{1} p(j) x(j) d j$ and the non-negativity constraints $x(j) \geq 0 \forall j$. $E$ denotes an agent's income. The sub-utility function $v(x)$ is concave, $v^{\prime}(x)>0$ and $v^{\prime \prime}(x)<0$, and the marginal utility is bounded from above, $v^{\prime}(0)<\infty$. With bounded marginal utility the nonnegativity constraints are potentially binding and the corresponding first order conditions for a variety $j$ are

$$
\begin{aligned}
v^{\prime}(x(j))=\lambda p(j) & \text { for } x(j)>0 \\
v^{\prime}(0)<\lambda p(j) & \text { for } x(j)=0
\end{aligned}
$$

where $\lambda$ is the Lagrange multiplier. Intuitively, an agent compares for every available variety $j$ the marginal utility from starting to consume this variety $v^{\prime}(0)$ with her utility costs $\lambda p(j)$ associated with buying a marginal unit of this variety. If the marginal costs are higher than the marginal utility the optimal quantity is zero - the non-negativity constraint binds. For all other varieties the optimal quantities are positive and are chosen such that the marginal rates of substitution equal relative prices. 
Figure 1 depicts the demand function for a particular variety $j$. Note that there is a finite price $v^{\prime}(0) / \lambda$ above which the optimal quantity is zero.

Figure 1

As the varieties enter the utility function symmetrically, agents simply order the varieties in their prices (think of reindexing the varieties such that the prices rise in the index $j$ ) and then choose up to which price they still want to consume positive quantities. I denote the index of this marginal variety by $M$. Its price follows from rearranging the first order condition (1) when the non-negativity constraint just binds, $p(M)=v^{\prime}(0) / \lambda$. As the indices are increasing in prices, $M$ also denotes the measure of varieties that are consumed in positive quantities and thus represents the extensive margin of consumption in this model. Because the goods spectrum is normalized to one the extensive margin of consumption simultaneously represents the share of available varieties consumed in positive quantities.

Assuming that the price distribution can be represented by a continuous cdf $G(p)$ - this will be the case in the general equilibrium - the share of consumed varieties (and therefore also the extensive margin of consumption) is

$$
M=G\left(v^{\prime}(0) / \lambda\right)
$$

For varieties $j<M$ the Marshallian demand follows from rearranging the first order condition, $x(\lambda p)=v^{\prime-1}(\lambda p)$. Inserting the Marshallian demand into the budget constraint and making the change of variable $p=G^{-1}(j)$ yields

$$
E=\int_{0}^{v^{\prime}(0) / \lambda} p x(\lambda p) g(p) d p
$$

implicitely determining the marginal utility of income $\lambda$ for a given price distribution $G(p)$ and income $E$. In the equilibrium we will know the price distribution and the income and thus be able to solve for the multiplier $\lambda$. Using (2) one then solves for the extensive margin of consumption and (1) determines the optimal quantities for varieties $j<M$. 


\subsection{Production technology and market structure}

The production technology exhibits constant returns to scale and uses one input ${ }^{4}$, which I call labor. Labor is assumed to be perfectly mobile within countries, but immobile across countries, so that in equilibrium there will be one wage rate $w_{i}$ per country. $z_{i}(j)$ denotes country $i$ 's productivity in producing variety $j$. Assuming perfect competition and iceberg trade $\operatorname{costs}^{5}-d_{n i}$ units need to be shipped in $i$ for one unit to arrive at the destination $n$ - implies that the price at which country $i$ offers variety $j$ in country $n$ is

$$
p_{n i}(j)=\frac{w_{i} d_{n i}}{z_{i}(j)}
$$

I follow EK and assume that the country-variety specific productivity $z_{i}(j)$ is the realization of a Fréchet distributed random variable $Z_{i}(j)$

$$
\operatorname{Pr}\left[Z_{i}(j) \leq z\right]=\exp \left\{-T_{i} z^{-\theta}\right\}
$$

$T_{i}$ is country specific and governs the expected productivity draw. I will therefore refer to $T_{i}$ as country $i$ 's technology (a higher $T_{i}$ implies a higher expected productivity and therefore represents a better technology in country $i$ ). $\theta$ is common to all countries and controls the variation in the productivities (the lower $\theta$ the more variation there is in productivity draws). I will show later on that $\theta$ also governs the elasticity of trade volumes with respect to trade cost, which is why I sometimes will call $\theta$ the trade elasticity.

\subsection{Equilibrium}

All countries $i$ are in principle able to produce each variety $j$. However, consumers will source each variety from only one producing country - the country offering the lowest price. International trade thus emerges if this country with the lowest price is a foreign country. In Appendix B.1 I show that the lowest prices on offer in country $n$ can be represented by a cdf

$$
G_{n}(p)=1-\exp \left\{-\Phi_{n} p^{\theta}\right\}
$$

\footnotetext{
${ }^{4}$ For parsimony I abstain from modeling multiple inputs. This will imply that in the calibration differences in non-tradable endowments (e.g. human and physical capital) and differing price-indices for tradable intermediates are absorbed into the calibrated technology. For non-tradable endowments and in the context of the counterfactuals this is admissible. For tradable intermediate inputs I will show in the robustness-section how the results change when allowing for them.

${ }^{5}$ I normalize trade costs within countries to one, $d_{n n}=1$ for all $n$, and assume that the triangle inequality, $d_{n i} \leq$ $d_{k i} d_{n k}$ holds for all $i, k$, and $n$.
} 
where

$$
\Phi_{n}=\sum_{i=1}^{N} T_{i}\left(w_{i} d_{n i}\right)^{-\theta} .
$$

I.e. $G_{n}(p)$ represents the share of varieties in country $n$ with a price (weakly) below $p$. As all agents are endowed with one unit of labor the income of a country $n$ agent is simply the wage rate, $w_{n}$ (to be endogenously determined). For a given wage rate the budget restriction (3) together with the price distribution therefore determines the marginal utility in country $n, \lambda_{n}$. The extensive margin of consumption in $n$ follows immediately,

$$
M_{n}=1-\exp \left\{-\Phi_{n}\left(v^{\prime}(0) / \lambda_{n}\right)^{\theta}\right\}
$$

In Appendix B.2 I derive the probability $\pi_{n i}$ that a producer country $i$ is the cheapest supplier in the importing country $n$ for a particular variety,

$$
\pi_{n i}=\frac{T_{i}\left(w_{i} d_{n i}\right)^{-\theta}}{\Phi_{n}}
$$

Since there is a continuum of goods, $\pi_{n i}$ is also the share of varieties for which country $i$ is the cheapest supplier in $n$. Because the probability is the same for all goods $\pi_{n i}$ is not only the share of the total goods spectrum, but also the share for any sub-spectrum; in particular also for an importing country's extensive margin of consumption. But this implies that the extensive margin of the bilateral trade flow from $i$ to $n$, which I denote by $m_{n i}$, is simply the importing country's extensive margin of consumption, $M_{n}$, multiplied by the share of varieties for which the exporter $i$ is the cheapest producer, $\pi_{n i}$,

$$
m_{n i}=\pi_{n i} M_{n}
$$

The source of the remarkable simplicity of this result is worth discussing: The distributional assumption of the EK framework implies that conditional on entering a market $n$ prices have the same distribution across supplier countries (Appendix B.3 provides the corresponding derivations). ${ }^{6}$ Therefore the prices of the goods that the importer $n$ actually buys bear no information about the likely source of these goods, so that $\pi_{n i}$ is the share of varieties of any subinterval of the variety space for

\footnotetext{
${ }^{6}$ Eaton and Kortum (forthcoming) call this feature "neutrality". Note that neutrality is not unique to the Ricardian framework. E.g. in the monopolistic competition model with heterogeneous firms and market entry costs neutrality follows if market entry costs are only destination specific and productivities are drawn from Pareto distributions. Costinot and Komunjer (2007) provide a discussion of general productivity distributions in the Ricardian multi-country framework.
} 
which the supplier $i$ offers the cheapest price in $n$ - in particular also for the subinterval $M_{n}$ representing the $M_{n}$ percent cheapest varieties.

Since the distribution of prices of goods that are actually sold in $n$ is the same across supplier countries $i$, average sales do not vary source neither. In particular, average sales in $n$ are given by total expenditures $w_{n} L_{n}$ divided by the extensive margin of consumption, $w_{n} L_{n} / M_{n}$. The aggregate value of the bilateral trade flow from $i$ to $n, X_{n i}$ is given by average sales multiplied by the the measure of varieties for which $i$ is the cheapest supplier in $n$ and which are actually consumed in positive quantities - the extensive margin of trade, $m_{n i}$ - which yields

$$
X_{n i}=\pi_{n i} w_{n} L_{n}
$$

Note that taking the derivative of the $\log$ of volumes with respect to the log of trade costs yields $\theta$ (neglecting general equilibrium effects on the wage rates) which is why $\theta$ is sometimes called the trade elasticity.

To close the model and determine the equilibrium wage vector I use the labor market clearing conditions $^{7}$

$$
w_{i} L_{i}=\sum_{n=1}^{N} \frac{T_{i}\left(w_{i} d_{n i}\right)^{-\theta}}{\sum_{k=1}^{N} T_{k}\left(w_{k} d_{n k}\right)^{-\theta}} w_{n} L_{n} \quad \text { for } i=1, \ldots, N
$$

In summary, the structure of the global economy is characterized by the countries' technologies, $T_{i}$, and populations, $L_{i}$, the matrix of bilateral trade costs, $d_{n i}$, the trade elasticity, $\theta$, and the shape of the utility function, $v(\cdot)$. In the general equilibrium producers price according to (4) and consumers choose their optimal quantities and extensive margins (6) as implied by (1). Market clearing (9) pins down the set of equilibrium wage rates and bilateral trade pattern are characterized by their aggregate value (8) and their extensive margin $(7) .^{8}$

\footnotetext{
${ }^{7}$ The labor market clearing condition follows for example from imposing balanced trade, $\sum_{k \neq i} X_{i k}=\sum_{n \neq i} X_{n i}$, and adding the domestically sourced consumption, $X_{i i}$, on both sides to get $\sum_{k=1}^{N} X_{i k}=\sum_{n=1}^{N} X_{n i}$. Total expenditures in $i$ are $w_{i} L_{i}=\sum_{k=1}^{N} X_{i k}$. Substituting for $X_{n i}$ and $\pi_{n i}$ on the right hand side then yields the labor market clearing condition as stated in the text.

${ }^{8}$ The general equilibrium exists and is unique. To see this note that the labor market clearing conditions can be rewritten as excess demands for labor. It is straight forward to show that the resulting system of excess demands satisfies the sufficient properties for existence and uniqueness (see for example Propositions 17.B.2 and 17.F.3 in MasColell, Whinston, and Green (1995)). The extensive margins and the optimal quantities are unique as they follow from maximizing a concave object over a convex constraint. As wages and extensive margins fully summarize the general equilibrium this implies that the general equilibrium is unique.
} 


\subsection{The role of per-capita incomes}

In this section I discuss how per-capita incomes affect trade pattern and contrast the results to the standard model with homothetic preferences. ${ }^{9}$ In the context of this paper the role of non-homothetic preferences is to endogenize the extensive margin of consumption. Figure 2 illustrates this by depicting equation (6).

Figure 2

The price of the marginal variety is $v^{\prime}(0) / \lambda_{n}$. Using the country specific price distribution $G_{n}(p)$ one gets the share of varieties with prices lower than this marginal price and thus the share (and measure) of varieties that are consumed in positive quantities - the extensive margin of consumption. An increase in per-capita income lowers the marginal utility of income $\lambda_{n}$ and thus increases the extensive margin of consumption - richer countries consume a broader set of varieties. A first order stochastic dominance shift in the price distribution increases the extensive margin of consumption as well - countries that are better integrated and have therefore lower prices will consume broader sets of varieties. Note finally that for $v^{\prime}(0) \rightarrow \infty$ the extensive margin goes towards one and agents would not adjust their extensive margins with income.

In the Ricardian model, a country's per-capita income depends on that country's technology - the better technology, the higher the wage rate and thus per-capita income. In the model there are two channels of how an importing country n's technology affects the extensive margin of trade. The first channel is the standard supply side channel. A better technology implies better productivity draws for more varieties so that the share of varieties $\pi_{n n}$ for which local producers offer the best prices rises. But this implies that the share of varieties that are imported, $\left(1-\pi_{n n}\right)$, and therewith the extensive margin of bilateral trade tends to fall. On the other hand the non-homothetic model exhibits a second channel. Better technology leads to higher wages and agents therefore extend their extensive margin of consumption, which tends to increase the extensive margin of trade. In the calibrated version of model it will turn out that the latter effect dominates so that the extensive margin of bilateral trade is positively correlated with per-capita incomes. In the homothetic model on the other hand only the first effect is present (all countries' extensive margins of consumption are one) and the correlation between extensive margin of trade and importer income is unambiguously negative. Note also that

\footnotetext{
${ }^{9}$ With homothetic preferences expenditure shares are constant. One can show that a linear transformation of the widely used CES-preferences is indeed the most general form of additively separable homothetic preferences. Note that homotheticity (for additive preferences) requires $v^{\prime}(0)=\infty$ as otherwise sufficiently poor agents do not buy an expensive variety, i.e. their expenditure share is zero, whereas the expenditure share of sufficiently rich agents is positive, which contradicts homotheticity.
} 
in the non-homothetic model the decomposition of aggregate gdp into population size and per-capita income matters - a rich, but small country has a high extensive margin of consumption and thus also tends to import broad sets of varieties, whereas the opposite is true for a poor, but large country although the two countries may have the same aggregate gdp.

Whereas the non-homothetic and the homothetic model can have opposing predictions for the extensive margin of bilateral trade, they exhibit the same pattern for the aggregate volumes. This feature will be very useful when calibrating the model and comparing its performance to the the homothetic model. Note also that with respect to aggregate volumes both models do not have separate roles for differences in per-capita incomes that are induced by differing technologies. ${ }^{10}$

\section{$3 \quad$ Quantifying the model}

In this section I quantify the model to assess whether my theory is able to explain the behavior of the extensive margin of trade. I calibrate the model parameters using data on aggregate trade volumes and US consumer behavior. I then simulate the parametrized model and compare the behavior of its extensive margin of bilateral trade with the data.

\subsection{Parametrization of the utility function}

I have shown above that the effects discussed emerge for a broad class of sub-utility functions $v(x)$. The central property is a bounded marginal utility, $v^{\prime}(x)<\infty$. To quantify the model I need to choose a parametric form for $v(x)$. I will use the Stone-Geary form

$$
v(x)=\log (\bar{x}+x)
$$

where $\bar{x} \geq 0$, as the thus parametrized model nests the standard homothetic model with $\bar{x}=0 .{ }^{11}$ The preference parameter $\bar{x}$ represents the degree of non-homotheticity. In the context of this paper it is particularly important that it governs the marginal utility of starting to consume an additional variety, $v^{\prime}(0)=1 / \bar{x}$. The closer the non-homotheticity parameter $\bar{x}$ gets to zero the larger the marginal utility

\footnotetext{
${ }^{10}$ In the data richer countries tend to trade more. One potential explanation is brought forward by Waugh (2010) who argues that richer countries have systematically lower trade costs. I will capture this in the calibration by following Waugh (2010)'s approach to modeling trade costs.

${ }^{11}$ For $\bar{x}=0$ the preferences become CES preferences with an elasticity of substitution of one. Since the quantitative behavior of the homothetic model is independent of the elasticity of substitution (see Alvarez and Lucas (2007)) the results represent the general CES model.
} 
ofs consuming new varieties and thus the weaker the demand side effects on the extensive margin of trade. For $\bar{x}=0$ the marginal utility approaches infinity and agents find it optimal to consume all available varieties no matter how expensive they are.

In the robustness section I will show that the results remain unchanged for alternative preferences specifications with bounded marginal utility such as quadratic preferences and CARA preferences.

\subsection{Calibration strategy}

The theoretical model's bilateral trade pattern are characterized by two moments - the extensive margins and aggregate volumes. Volumes are governed by

$$
X_{n i}=\pi_{n i} w_{n} L_{n}
$$

and the extensive margins are

$$
m_{n i}=\pi_{n i} M_{n}
$$

Labor market clearing $w_{i} L_{i}=\sum_{n=1}^{N} X_{n i}$ determines the equilibrium wage rates and the equilibrium extensive margins of consumption follow from the budget restriction (3). In Appendix B.4 show that with Stone-Geary preferences the budget restriction can be written as

$$
w_{n}=\bar{x}\left(\Phi_{n}\right)^{-\frac{1}{\theta}}\left(M_{n}\left(-\log \left(1-M_{n}\right)\right)^{\frac{1}{\theta}}-\gamma\left(\frac{1}{\theta}+1 ;-\log \left(1-M_{n}\right)\right)\right),
$$

where $\gamma(z, \bar{t})=\int_{0}^{\bar{t}} t^{z-1} e^{-t} d t$ is the incomplete Gamma function.

The model parameters are the countries technologies $T_{i}$ and populations $L_{i}$, the bilateral trade $\operatorname{costs} d_{n i}$, the non-homotheticity parameter $\bar{x}$, and the trade elasticity $\theta$. Whereas the populations can be taken from the data, I need to calibrate the remaining parameters. In the following I describe how I calibrate these parameters. The data used for the calibration is discussed en passant with a more complete description in Appendix A. ${ }^{12}$ I start with the calibration strategy for the non-homotheticity parameter as this is the most novel part of the model. I then discuss the trade elasticity, trade costs, and technologies in turn. The sample consists of 164 countries and I consider the year 2003. Table 6 lists the countries in the sampe.

\footnotetext{
${ }^{12}$ The MATLAB code used for the calibration is available upon request.
} 


\subsubsection{Non-homotheticity parameter}

To calibrate the non-homotheticity parameter I use data of the US Consumer Expenditure Survey (CEX) of the year 2003. The advantage of using this source is its independence from the trade data. Based on this database I construct the expenditures of around 3000 households for 107 different categories of tradable goods such as "Encyclopedia and other sets of reference books", "Wigs, hairpieces, or toupees ", and "Winter sports equipment". Details can be found in Appendix A.5. Counting the categories with positive expenditure gives me a measure for the extensive margin of consumption of a household. Table 2 reports the elasticity of this measure of the extensive margin with respect to total expenditures controlling for demographic variables such as household size, age of the reference person, and geography, i.e. rural/urban and region (Northeast, Midwest, South, West).

Table 2

Table 2 also reports the elasticities for a more liberal expenditure classification that comprises 186 categories. ${ }^{13}$ Clearly, the positive elasticity is robust across specifications lying between 0.4 and 0.5 . For the calibration I will target the elasticity associated with the conservative classification and the specification including all controls, 0.41 .

To understand the details of the calibration, first note that for trade volumes only the relative technologies matter, which implies that we cannot identify the absolute level of the technologies using aggregate trade volumes. In the budget constraint (10) on the other hand the absolute level of technologies is relevant since it determines the level of $\Phi_{n}$. Moreover note that scaling all technologies by a constant has the same effect as scaling the non-homotheticity parameter. Therefore I can normalize either the level of technologies or the preference parameter. It is convenient to choose to normalize the level of the technologies such that the US-aggregator, $\Phi_{U S}$, equals one. Then the budget constraint of a US-agent $h$ with income $w_{h}$ is

$$
w_{U S, h}=\bar{x}\left(M_{U S, h}\left(-\log \left(1-M_{U S, h}\right)\right)^{\frac{1}{\theta}}-\gamma\left(\frac{1}{\theta}+1 ;-\log \left(1-M_{U S, h}\right)\right)\right) .
$$

Setting $\theta=4.5$ (see next section) and for a given non-homotheticity parameter $\bar{x}$ I can feed all the CEX households' incomes into the budget constraint and calculate corresponding extensive margins of

\footnotetext{
${ }^{13}$ The main difference lies in the treatment of housing- and gender-related categories. The conservative classification excludes these categories, whereas the liberal classification aggregates over categories that represent the same item but differentiate by renter and owner or women, men, girls, and boys.
} 
consumption. I then choose the preference parameter such that the resulting elasticity of the extensive margin of consumption matches the empirical CEX elasticity. ${ }^{14,15}$

\subsubsection{Trade elasticity}

For the trade elasticity I take the value estimated by Simonovska and Waugh $(2010), \theta=4.5$. In general, one cannot separately identify the trade elasticity and the level of trade costs by estimating a gravity equation - the trade elasticity may be high and trade costs low or conversely, the elasticity low and trade costs high. To tackle this problem EK argue that one can use disagregated price data from the Worldbank's International Comparison Project (ICP) and take the maximal (or second highest) within good price difference as an estimate for bilateral trade costs. As the resulting value for trade costs has been obtained independently from trade volumes one then can solve for the trade elasticity that is implied by a gravity type regression. Simonovska and Waugh (2010) extend this approach. They provide a more elaborate estimation strategy that controls for an aggregation bias arising from the fact that due to the small number of goods categories in the ICP (around 80) it is very unlikely that the highest price difference represents actually the trade costs. They also use a broader set of countries (123) and are thus able to check if the trade elasticity systematically varies with development level, which they find is not the case. The structural framework for their estimation is the EK model. Since my model behaves similar to the EK model with respect to volumes and prices I can directly adapt the Simonovska and Waugh (2010) baseline estimate of $\theta=4.5$.

\subsubsection{Trade costs}

I calibrate the trade costs using aggregate bilateral trade volumes of the year 2003. In particular I follow Waugh (2010) in modeling unobserved trade costs as a function of observed proxies and an exporter fixed effect

$$
d_{n i}=\exp \left\{\delta_{k}+b+l+e x_{i}+\varepsilon_{n i}\right\},
$$

\footnotetext{
${ }^{14}$ The resulting value is $\bar{x}=3.14$. In contrast to for example the elasticity of substitution of CES-preferences this parameter does not have a standalone interpretation (beyond the fact that it is not zero) since measures such as the demand elasticity or elasticity of substitution change with income and prices. Therefore $\bar{x}$ is only meaningful when income and price distribution are known or as in the case here, when a model giving rise to income and prices is parametrically specified.

${ }^{15} \mathrm{On}$ a first sight the fact that I use within country inequality to calibrate a model where countries are populated by representative agents may seem surprising. I address this objection in the robustness section, where I consider the potential role of within-country inequality. Also I refer to the well-established practice in the macro literature using microeconomically estimated elasticities to calibrate macro models populated by representative agents.
} 
where I suppressed the associated dummy variables for expositional simplicity. $\delta_{k}(k=1, \ldots, 6)$ is the effect of the bilateral distance between countries $i$ and $n$ lying in in the $k$ th distance interval. The intervals are (in miles): $[0,375),[375,750),[750,1500),[1500,3000),[3000,6000)$, and $[6000, \infty) . b$ is the effect of sharing a border, and $l$ the effect of having the same language. $e x_{i}$ is an exporter fixed effect that allows for asymmetry in bilateral trade costs and $\varepsilon_{n i}$ captures all other trade barriers and is assumed to be orthogonal to the exporter fixed effects, distance, border, language, and membership in the same trade agreement.

Normalizing the volume of the bilateral trade flow from $i$ to $n$ (equation (8)) with the importer's home sales $X_{n n}$ yields

$$
\frac{X_{n i}}{X_{n n}}=\left(d_{n i}\right)^{-\theta} \frac{S_{i}}{S_{n}}
$$

where $S_{i}=T_{i}\left(w_{i}\right)^{-\theta}$ is a country fixed effect. The value of the bilateral trade flow $X_{n i}$ is observed, whereas - in the context of the model - $X_{n n}$ is simply a country's aggregate gdp less its total imports. ${ }^{16}$ Imposing above trade cost function yields a Gravity-type equation that I estimate using the Poisson pseudo-maximum likelihood estimator proposed by Silva and Tenreyro (2006). Table 3 reports the resulting estimates for the trade cost parameters together with the associated effects on trade costs and some summary statistics on the estimated trade costs.

Table 3

The average and median trade costs among OECD countries are 2.01 and 1.89 respectively, which is slightly higher than often cited 1.7 suggested by Anderson and Van Wincoop (2004) and very much in line with Waugh (2010). Consistent with the findings in the literature trade costs among non-OECD countries are considerably higher.

\subsubsection{Technologies}

The most straightforward approach to recovering technologies is to follow Fieler (2010) and take percapita incomes ${ }^{17}$ as a proxy for wages - indeed in the model wages and per-capita incomes coincide.

\footnotetext{
${ }^{16}$ It is important to mention two potential caveats related to the way the model is mapped to the data. First, I use aggregate trade volume, which includes also non-consumption goods such as intermediates. Second, whereas trade is measured in gross values gdp is measured as value added, which again in the context of intermediates may be of importance. I address both caveats in the robustness section where I extend the model to allow for intermediates. It turns out that the main results remain basically the same. The reason for this may be that the share of consumption goods in trade flows is unrelated to per-capita gdp and aggregate gdp, so that no systematic bias emerges.

${ }^{17}$ In the context of the model using nominal incomes is appropriate as deviations from PPP are endogenous in the EK framework.
} 
Using the estimates for the country fixed effects, $\hat{S}_{i}$, one then can directly solve for the implied technologies, $\hat{T}_{i}=\hat{S}_{i}\left(w_{i}\right)^{\theta}$. An alternative approach disregards the country fixed effects and uses the market clearing conditions (9) to recover the technologies: Plugging the per-capita incomes, the estimated trade costs and the trade elasticity into the market clearing conditions allows me to solve for the unique set of technologies for which all markets clear. Figure 3 plots the expected productivity draw in a country, $E_{i}[z]=T_{i}^{1 / \theta}$, against its per-capita income.

Figure 3

Clearly the two approaches yield very similar technologies. Moreover, as it is to expect there is a high correlation between estimated technology and observed incomes. However, note that the correlation is not perfect as different geographic locations imply that countries with the same technology face differing levels of demand and thus have different equilibrium incomes. For the remainder of the paper I use the technologies calibrated using the market clearing conditions. ${ }^{18}$

\subsection{Calibration results}

Given the calibrated parameters I now can simulate the model and compare the behavior of its extensive margin to the data. Remember that with respect to volumes the non-homothetic model behaves similar to the homothetic model. Hence, as we used volumes to calibrate technologies and trade costs, these calibrated values also apply to the homothetic model. I.e. we obtain the homothetic model's predictions simply by setting the non-homotheticity parameter to zero, $\bar{x}=0$.

The motivating fact of this paper is the positive correlations between the extensive margin of bilateral trade and the per-capita incomes of the trading partners. Table 4 reports the income elasticities that follow from repeating the regressions cited in the introduction using the model data.

Table 4

For the exporter income elasticity both models yield the same elasticity. Moreover the elasticity is reasonably close to what is observed in the data. For the importer income elasticity on the other hand only the non-homothetic model's sign is consistent with the data. With 0.63 the non-homothetic

\footnotetext{
${ }^{18}$ The results for the alternative technologies are very similar with differences in the outcomes typically lying within $1-2 \%$.
} 
model's elasticity is somewhat higher than the data's income elasticity of around 0.5, but still reasonably close. The homothetic model on the other hand predicts a negative importer income elasticity of -0.12. The reason for this counterfactual prediction is its negligence of the extensive margin of consumption. So that only the negative effect of a technologically advanced country producing more varieties locally is present. In the non-homothetic model this negative effect is dominated by a positive effect coming from the demand side - the expanding extensive margin of consumption. Figure 4 plots the calibrated extensive margin of consumption against per-capita income.

Figure 4

Note that the relation is not perfect. The reason for that are differences in the remoteness. Spain and New Zealand for example had the same nominal per-capita income in 2003, however Spain's calibrated extensive margin of consumption is almost 10\% higher than New Zealand's as Spain's geographic location is much more favorable. This means that prices tend to be lower in Spain so that its real income is higher and agents find it optimal to consume a broader set of varieties.

\subsection{The quantitative importance of the demand side}

In this section I perform two counterfactual experiments. The goal of these exercises is to demonstrate that accounting for demand side effects is quantitatively important when thinking about the reaction of the extensive margins of trade to changes in the economic environment. In each case I start with the world economy as calibrated in the previous section and compare the counterfactual outcome to the initial situation.

\subsubsection{The rise of China and India}

One of the most important trends in the global economy is the rise of China and India. These two countries experienced spectacular growth rates in the recent years - according to the World Development Indicators (Worldbank, 2010) China's per-capita income almost doubled (95\%) relative to the world per-capita income between 1993 and 2003, important India's per-capita income grew by 31\% relative to world per-capita income. In this experiment I consider the calibrated 2003 world economy and ask how trade pattern would change if China's and India's technologies improve such that their incomes rose again by the same magnitudes relative to the world income. 
The homothetic model predicts that because China and India's technologies improve these two countries become competitive in more varieties. Therefore these countries export broader sets of varieties (the median increase is $76 \%$ for China and $17 \%$ for India). At the same time the better technology implies also that these countries import a narrower set of varieties. In important China is predicted to source $54 \%$ more varieties locally, whereas India's home share extends by $2 \%$. This translates into median decreases in the extensive margin of bilateral import flows of $15 \%$ and $14 \%$ for China and India respectively.

These predictions turn when one allows for non-homothetic consumer behavior. In the nonhomothetic model China and India extend their extensive margin of consumption as their incomes increase ( $82 \%$ in China and $34 \%$ in India), so that the measures of imported varieties actually increase by $53 \%$ and $33 \%$. This translates into median increases in the extensive margins of bilateral import flows of $55 \%$ for China and $14 \%$ for India.

\subsubsection{Changes in trade costs}

In a second experiment I consider the effect of reductions in trade costs. Lower trade costs affect the extensive margin of trade trough two channels. The first channel is the standard supply side channel - lower trade costs imply that trade becomes worthwhile for more varieties, i.e. the extensive margin of trade will expand. However, there is a second channel operating trough the demand side - lower trade costs lead to lower prices ${ }^{19}$ which increases real incomes. With higher incomes agents will find it optimal to consume broader sets of varieties, which in turn will tend to increase the extensive margins of trade. In order to assess the relative importance of these two channels I take again the calibrated 2003 world economy and uniformly decrease trade costs by 10, 25, and 50 percent.

From Table 5 reporting summary statistics on the percentage changes in the extensive margins of bilateral trade the starkly differing predictions of the homothetic and the non-homothetic model become apparent.

Table 5

The homothetic model for example predicts that for a $25 \%$-reduction in trade costs more than halve of country-pairs actually experience reductions in the bilateral extensive margins. This is because low-tech supplier countries were competitive in nearby markets in the initial situation with high trade

\footnotetext{
${ }^{19}$ Above I chose the US wage as the numéraire. Therefore I describe the adjustment via lower prices. Alternatively with some goods price as the numéraire the corresponding adjustment would be described by lower trade costs increasing productivity and therewith wages.
} 
costs, but lower trade costs imply that they are now dominated by countries with better technologies such that their export margins tend to fall. In the non-homothetic model this supply-side effect is attenuated by the demand-side effect of a rising extensive margin of consumption, the absolute and relative changes in which are plotted in Figure 5 against per-capita incomes.

Figure 5

Whereas poor countries experience the highest relative changes, middle income countries have the highest absolute changes. Relative to the supply side effect these changes are large such that for example the number of country pairs experiencing falling extensive margins goes back to $15 \%$ and the predicted median change is an increase of $22 \%$ instead of a decrease of $1 \%$ in the homothetic model. These contrasting predictions demonstrate that it is indeed important to account for demand side effects when thinking about the extensive margin of bilateral trade.

\section{How general is the proposed channel?}

I have presented a model of international trade where agents adjust their extensive margin of consumption with income, which has quantitatively important effects for the extensive margin of bilateral trade. In order to highlight this novel demand side channel, I kept the supply side very simple by adapting a perfectly competitive Ricardian framework. I found that when allowing for non-homothetic consumer behavior the EK model is not only able to capture the pattern of aggregate trade volumes, but also the behavior of the extensive margin of trade. The more general message is that the extensive margin of trade may be driven by a considerable amount trough differences in demand pattern across countries. In the following I discuss how this channel generalizes to richer models and why accounting for the demand side is potentially important.

A richer model of international trade would model the firm explicitly by allowing for market power as in Krugman (1980) and Melitz (2003). Fixed market entry costs implied that not all firms find it optimal to enter all markets, which gives rise to an extensive margin of trade. In particular, for a given level of entry costs, it is more attractive to enter bigger markets since the contribution margin in these markets is larger. With homothetic preferences the notion of a "big market" is purely driven by aggregate gdp - due to constant expenditure shares it does not matter if we have a large and poor population or a small and rich population. With non-homothetic preferences however the decompo- 
sition of aggregate gdp becomes relevant as poor agents adjust their expenditure shares with income. In the model developed above this is particularly apparent when the expenditure share goes from zero (when the non-negativity constraint is binding) to some positive share - the thus emerging extensive margin of consumption then drives the extensive margin of trade. In a more general setting with market entry costs it is not only the bounded marginal utility that is relevant but also poor agents relatively concentrating their expenditures on cheap goods. A small, but rich market may therefore be sufficiently "big", whereas demand in the poor, but populous market (with the same aggregate gdp) may be too low for the operating profits to cover market entry costs - accordingly the small, but rich market's extensive margins of import flows will tend to be higher than the ones of the large, but poor market. Clearly, in such a framework it would not only be average income, but also the entire shape of the income distribution that is relevant for a firm's entry decision. Ignoring non-homothetic demand thus leads a researcher to attribute differences in the extensive margins of import flows entirely to differences in market entry costs, whereas a considerable part of it may be driven by differences in average income and the income distribution.

\section{Robustness and extensions}

\subsection{Extending the model to trade in intermediates}

The model I developed above is one of consumption goods only. I chose to abstract from intermediate goods to keep the model as simple as possible. In this section I outline a model with intermediate goods and final goods - both tradable. The purpose of this extension is twofold: First, I use the extended model to assess if abstracting from intermediate goods introduces a significant bias in the quantification. Second, to compute the left hand side of equation (11) I used trade and gdp data. However, many papers using the EK framework are models of trade in intermediates, in the context of which gross manufacturing output is used instead of gdp data. With the intermediate extension I will need to use gross manufacturing output and thus one can assess by how much the results were driven by these different ways of computing the normalized trade flows.

In the extended model there are two industries, $\iota=I, F . I$ produces tradable intermediate goods and $F$ produces tradable final goods. ${ }^{20}$ Both industries bundle labor and a CES-aggregate of intermediates using a Cobb-Douglas production technology with labor share $\beta$. Cost minimization implies

\footnotetext{
${ }^{20}$ Note that in EK and follow up papers it is usually assumed that final goods are non-traded.
} 
that the price of at which country $i$ can offer a industry $\iota$-variety $j_{\iota}$ in market $n$ is

$$
p_{n i}\left(j_{\iota}\right)=\frac{d_{n i}}{z_{i}\left(j_{\iota}\right)} w_{i}^{\beta} P_{i}^{1-\beta}
$$

where $P_{i}=\left(\int_{0}^{1} p\left(j_{I}\right)^{1-\sigma} d j_{I}\right)^{1 /(1-\sigma)}$ is the CES price index. ${ }^{21}$ I omitted a constant depending on the labor share $\beta$. For expositional simplicity I will omit constants in the following formulas, which corresponds to a particular normalization of technologies. Assuming Fréchet distributed productivities with similar parameters across industries yields a gravity-like expression that looks in its reduced form similar to the one derived above

$$
\frac{X_{n i}}{X_{n n}}=\left(d_{n i}\right)^{-\theta} \frac{S_{i}}{S_{n}}
$$

However, there are two crucial differences: First, total demand, $X_{n}$, is now the total intermediate absorption, $X_{n}^{I}$, plus total final goods demand, $X_{n}^{F}$. Consequently, following EK the home supply now has to be imputed by subtracting a country's total manufacturing exports from its gross manufacturing output, which I mostly get from UNIDO (2003) (details in Appendix A.6). Data constraints reduce the sample to 71 countries. Second the country fixed effects include now the countries' intermediate price indices, $S_{i}=T_{i}\left(w_{i}^{\beta} P_{i}^{1-\beta}\right)^{-\theta}$. Note that in the simple model without intermediates the price indices $P_{i}$ were absorbed into the calibrated technologies and wages entered with an exponent of one, which implies that the model tended to overstate the dispersion in technologies (standard deviation in $\log$ of technologies is 2.7 with intermediates ${ }^{22}$ vs. 7.5 without intermediates). Explicitly considering intermediates may particularly matter for counterfactual experiments changing the trade costs, as this implies potentially large changes in the intermediate price indices.

Using the same procedure as in the main text (but a different measure for $X_{n n}$ ) I can estimate the trade costs and the country fixed effects. To recover technologies there are again two approaches: The more direct approach uses the estimated country fixed effects, $\widehat{S}_{i}$ and trade costs, $\hat{d}_{n i}$, to compute the implied price indices, $\hat{P}_{n}=\left(\sum_{i=1}^{N} T_{i}\left(w_{i}^{\beta} P_{i}^{1-\beta} d_{n i}\right)^{-\theta}\right)^{-1 / \theta}=\left(\sum_{i=1}^{N} \hat{S}_{i}\left(\widehat{d}_{n i}\right)^{-\theta}\right)^{-1 / \theta}$ and then use these price indices together with the per-capita incomes, $w_{i}$, and calibrated values for $\beta$ and $\theta$ to solve for the implied technologies, $\widehat{T}_{i}=\widehat{S}_{i}\left(w_{i}^{\beta} \widehat{P}_{i}^{1-\beta}\right)^{\theta}$. Alternatively, one can combine the estimated trade costs and the per-capita incomes and solve directly for the unique set of technologies for which all markets clear. ${ }^{23}$ The correlation (in logs) between the thus calibrated technologies is very high at

\footnotetext{
${ }^{21} \mathrm{I}$ assume that trade costs and labor share are the same across the two industries.

${ }^{22}$ The standard deviation of $\log \left(T_{i} P_{i}^{-(1-\beta) \theta}\right)$, i.e. the technologies with absorbed intermediate price index is 2.9 .

${ }^{23}$ Specifically, I take an initial guess for the technology vector, compute the implied price indices, and use these together
} 
0.96. I use the technologies based on imposing market clearing.

The price distribution of final goods in country $n$ is

$$
G_{n}(p)=1-\exp \left\{-p^{\theta} \sum_{i=1}^{N} T_{i}\left(w_{i}^{\beta} P_{i}^{1-\beta} d_{n i}\right)^{-\theta}\right\} .
$$

Normalizing technologies such that $\sum_{i=1}^{N} T_{i}\left(w_{i}^{\beta} P_{i}^{1-\beta} d_{U S i}\right)^{-\theta}=1 \mathrm{I}$ can use the same value for the non-homotheticity parameter as above. Simulating the thus calibrated model yields an importer income elasticity of the extensive margin of bilateral trade of 0.58 (the corresponding elasticity in the model without intermediates is 0.57 whereas the empirical elasticity is 0.50 in the restricted sample of 71 countries). Considering the counterfactual experiments, the model with intermediates generally features even stronger differences between the predictions of the homothetic and the non-homothetic model. This is because the intermediate price index reacts to changes in trade costs or technologies respectively, which amplifies the reaction of the price distribution of final goods and thus agents tend to adjust their extensive margins of consumption more strongly.

\section{$5.2 \quad$ Inequality}

Up to now I abstracted from within-country inequality and had each country populated by representative agents. Although most of the global inequality is indeed explained by differences in average incomes, within-country inequality is a potentially important determinant for the extensive margin of trade - consider two countries with the same average income, but one with a wider range of the income distribution. My model would predict that the country with the richer agents has a broader extensive margin of consumption and thus tends to import more varieties. ${ }^{24}$

Taking my model literally implies that if each country features one very rich agents all countries extensive margins of consumption were one and all the demand side effect disappeared. I.e. this model's extensive margin is very sensitive to the upper tail of the income distribution. The main theoretical reason why this may not be the case is the presence of fixed market entry costs (beachhead costs). Incorporating these into my model would require departures from the competitive setting to allow for positive markups that can be used to cover the beachhead costs, which would disproportionally

with the initial guess to compute $\pi_{n i}$ and then the countries' balances of payments. I adjust the technology guess using a tâtonnement-like algorithm until all markets clear.

${ }^{24}$ Indeed, when repeating the regressions cited in the introduction including the importer's top-quintile of the income distribution I get positive coefficients for the top-quintile. The elasticity considering consumption goods only is 0.23 and significant at the $1 \%$ level, whereas the elasticity for all types of goods is lower at 0.15 and significant only at the $10 \%$ level. 
complicate the model. ${ }^{25}$

In order to nonetheless get a feeling for the potential importance of the within-country income distribution I propose a simple exercise that allows me to stay within the Ricardian framework. In particular I choose to use the average income in the top quintile to compute the extensive margin of consumption: Remember that conditional on entering market $n$ the price distribution is the same across supplier countries. Therefore agents will have the same average expenditures across countries, which implies that $\pi_{n i}$ is the expenditure share of each agent independent of his total expenditures. Consequently the aggregate value of the flow from $i$ to $n$ is still $X_{n i}=\pi_{n i} w_{n} L_{n}$. I.e. aggregate volumes do not depend on the income distribution so that we can use the same calibration strategy as above. The non-homotheticity parameter $\bar{x}$ calibrated using the CEX data remains unchanged. However, I acknowledge the presence of within-country inequality by using the average income among the top quintile in the budget constraint (10) instead of per-capita income. Taking the model literally this amounts to allowing for a general income distribution that is bounded by the average income in the top quintile. In a more general sense I hope to learn from this exercise how the results change when trying to account for differences at the top of countries' income distributions.

I use quintile data from UNU-WIDER (2008) that are described in detail in Appendix A.7. As the quintiles are not available for the full sample I consider a smaller sample of 112 countries. I reestimate the model parameters for this smaller sample of countries. ${ }^{26}$ Accounting for within-country inequality by using average incomes in the top quintiles in the budget constraint yields a lower importer income elasticity of 0.52 (vs. 0.46 in the data).

\subsection{Alternative utility functions}

In the theory part I worked with a general utility function with the crucial feature of a bounded marginal utility. For the quantification I then had to assume some particular functional form for the utility function (Stone-Geary). This section considers two alternative utility functions with bounded marginal utility and shows that the calibration results are robust to the particular functional form. I

\footnotetext{
${ }^{25}$ With non-homothetic preferences markups become endogenous. With a representative agent the model still preserves some tractability (see Simonovska (2010)) as per market there is one cutoff productivity above which firms enter this market and below which firms abstain from entering. However, if one introduces within-country inequality firms not only decide whether to enter a market or not, but also whom to supply in this market. I.e. the equilibrium is characterized by a correspondence between productivity and income of the agent that just consumes this firms variety at the optimal quantity of zero. Unfortunately, there is no simple expression for this correspondence. Since each country has its own productivity and income distributions, there are $N^{2}$ such correspondences, which is the reason why the model loses all its tractability.

${ }^{26}$ For this smaller sample of countries the calibrated importer income elasticity for the representative agent model barely changes (0.62 instead of 0.63).
} 
only consider one-parameter utility functions as my calibration strategy for the demand side targets only one moment.

In particular, I consider quadratic utility

$$
v^{q u a d r}(x)=x-\frac{1}{2} a^{q u a d r} x^{2}
$$

which is popular for its linear demand functions and constant absolute risk aversion utility (CARA)

$$
v^{\text {cara }}(x)=-\exp \left\{-a^{\text {cara }} x\right\}
$$

A reader might note that often these utility functions are written with three parameters. ${ }^{27}$ However, in the context of a static trade model utility functions have a pure ordinal purpose so that all monotonic transformations of the utility function, $U=\int v(x(j)) d j$, yield the same economic behavior. ${ }^{28}$ The one-parameter versions above are simply linear transformations of the often seen three parameter versions.

As aggregate trade volumes do not depend on the particular functional form of the utility function the supply side parameters calibrated above (trade elasticity, trade costs, technologies) still apply, i.e. I only need to recalibrate the demand side parameter. In Appendix B.5 I derive the analog to equation (10) governing the extensive margin of consumption for a given income and price distribution. Using these equations I calibrate the new utility parameters by targeting US consumers' income elasticity of the extensive margin consumption. ${ }^{29}$ I then simulate the calibrated models and calculate the income elasticities of the extensive margin. The resulting exporter income elasticities are the same as above as they do not depend on the demand side of the model. The importer income elasticities on the other hand crucially depend on the demand side as demonstrated above when comparing the homothetic model with the non-homothetic model. However, when considering the alternative non-homothetic utility functions the importer income elasticities change only very little (0.618 for CARA and 0.623 for quadratic preferences instead of 0.614 for Stone-Geary). Similarly, the quantitative effects in the counterfactual experiments do not significantly change. These results demonstrate that whereas accounting for non-homotheticity when thinking about the extensive margin of trade is very important, the quantitative behavior does not seem to depend very much on the particular functional form.

\footnotetext{
${ }^{27} v^{\text {cara }}(x)=B^{\text {quadr }}-C^{\text {quadr }} \exp \left\{-a^{\text {quadr }} x\right\}$ and $v^{\text {quadr }}(x)=B^{\text {cara }}+C^{\text {cara }} x-1 / 2 a^{\text {cara }} x^{2}$.

${ }^{28} \mathrm{It}$ is important to note, that the transformation is applied to the aggregate utility function, $U$, and not directly to the sub-utility function.

${ }^{29}$ The resulting parameters are $a^{q u a d r}=3.59$ and $a^{\text {cara }}=0.33$.
} 


\section{Conclusions}

In this paper I discuss the importing country's demand structure as a determinant of the extensive margin of bilateral trade. I draw on the evidence of microeconomic studies that show that richer agents consume more variety. Allowing for such an extensive margin of consumption in an otherwise standard Ricardian trade model offers an explanation for the positive correlation between the extensive margin of bilateral trade and the importers per-capita income. I quantify the model using data on aggregate trade volumes, and US consumer behavior. I find that the calibrated model's extensive margin of trade behaves similar to what we observe in the data. Two counterfactual experiments demonstrate that this novel demand side channel is quantitatively important.

I mentioned in the introduction that other authors have used non-homothetic preferences to discuss different aspects of the pattern of international trade such as aggregate volumes and quality. A potentially fruitful avenue for future research is a model where these two aspects and the extensive margin of trade could be analyzed simultaneously. On the demand side, such a framework would feature agents that adjust their consumption decision at the intensive, the extensive, and the quality margin. On the supply side variations in countries abilities to produce quality goods would introduce

comparative advantages. Trade pattern - volumes, extensive margin, and quality - could then be analyzed as the result of interactions of the exporter country's production structure and the importer country's demand pattern. 


\section{References}

Alvarez, F., And R. LuCAS (2007): "General equilibrium analysis of the Eaton-Kortum model of international trade," Journal of Monetary Economics, 54(6), 1726-1768.

Anderson, J., And E. VAn Wincoop (2004): "Trade costs," Journal of Economic Literature, 42(3), $691-751$.

BAldwin, R., And J. HARrigan (2007): "Zeros, quality and space: trade theory and trade evidence," NBER Working Paper No. 13214.

BLS (2003): "2003 consumer expenditure interview survey, public use microdata, documentation," U.S. Department of Labor, Bureau of Labor Statistics, Division of Consumer Expenditure Surveys.

Broda, C., And D. Weinstein (2006): "Globalization and the gains from variety," Quarterly Journal of Economics, 121(2), 541-585.

Choi, Y., D. Hummels, and C. Xiang (2009): "Explaining import quality: the role of the income distribution," Journal of International Economics, 78(2), 293-303.

Costinot, A., and I. Komunjer (2007): "What goods do countries trade? New Ricardian predictions," NBER Working Paper No. 13691.

Dollar, D., And A. KraAy (2002): "Growth is good for the poor," Journal of economic growth, $7(3), 195-225$.

Eaton, J., And S. Kortum (2002): "Technology, geography, and trade," Econometrica, 70(5), 17411779.

EATON, J., AND S. KorTum (forthcoming): Technology in the global economy: a framework for quantitiative analysis.

Eaton, J., S. Kortum, and F. Kramarz (2004): "Dissecting trade: firms, industries, and export destinations," American Economic Review, 94(2), 150-154.

Fajgelbaum, P., G. Grossman, and E. Helpman (2009): "Income distribution, product quality, and international trade," NBER Working Paper No. 15329.

FAlkinger, J., And J. Zweimüller (1996): "The cross-country Engel curve for product diversification," Structural Change and Economic Dynamics, 7(1), 79-97. 
Feenstra, R. (1994): "New product varieties and the measurement of international prices," American Economic Review, 84(1), 157-177.

Fieler, A. C. (2010): "Non-homotheticity and bilateral trade: evidence and a quantitative explanation," mimeo, University of Pennsylvania.

Foellmi, R., C. Hepenstrick, and J. Zweimüller (2010): "Non-homothetic preferences, parallel imports and the extensive margin of international trade," CEPR Discussion Paper No. 7939.

Gaulier, G., S. Zignago, D. Sondjo, A. Sissoko, and R. Paillacar (2010): "BACI: a world database of international trade at the product-level, 1995-2007 version," Centre d'Etudes Prospectives et d'Informations Internationales Working Paper No. 2010-23.

Gronau, R., and D. Hamermesh (2008): "The demand for variety: a household production perspective," Review of Economics and Statistics, 90(3), 562-572.

Hummels, D., And P. KLEnow (2002): "The variety and quality of a nation's trade," NBER Working Paper No. 8712.

JACKSON, L. (1984): "Hierarchic demand and the Engel curve for variety," Review of Economics and Statistics, pp. 8-15.

JekAnowski, M., And J. Binkley (2000): "Food purchase diversity across US markets," Agribusiness, 16(4), 417-433.

Krugman, P. (1980): "Scale economies, product differentiation, and the pattern of trade," American Economic Review, 70(5), 950-959.

LI, N. (2010): "An Engel curve for variety," mimeo, University of Berkeley.

Markusen, J. (2010): "Putting per-capita income back into trade theory," NBER Working Paper No. 15903.

Mas-Colell, A., M. Whinston, and J. Green (1995): Microeconomic theory. Oxford University Press, New York.

Melitz, M. (2003): "The impact of trade on intra-industry reallocations and aggregate industry productivity," Econometrica, 71(6), 1695-1725. 
Moon, W., W. Florkowski, L. Beuchat, A. Resurreccion, P. Paraskova, J. Jordanov, and M. Chinnan (2002): "Demand for food variety in an emerging market economy," Applied Economics, 34(5), 573-581.

Sauré, P. (2009): "Bounded love of variety and patterns of trade," Swiss National Bank Working Paper No. 2009-10.

Silva, J., And S. Tenreyro (2006): "The log of gravity," Review of Economics and Statistics, 88(4), $641-658$.

Simonovska, I. (2010): "Income differences and prices of tradables," NBER working paper No. 16233.

Simonovska, I., And M. Waugh (2010): "The Elasticity of trade for developing nations: estimates and evidence," mimeo, University of California, Davis.

Thiele, S., And C. Weiss (2003): "Consumer demand for food diversity: evidence for Germany," Food Policy, 28(2), 99-115.

UNIDO (2003): Industrial statistics database. United Nations Industrial Development Organization.

UNU-WIDER (2008): "World income inequality database, version 2.0c," World Institute for Development Economics Research of the United Nations University.

Waugh, M. (2010): "International trade and income differences," American Economic Review, forthcoming.

WorLD BANK (2010): World development indicators. World Bank. 


\section{A Data}

I use data for the year 2003. In the baseline specification the sample consists of 164 countries, which corresponds to $26732=164 * 163$ bilateral trade relations. Table 6 lists the countries in the sample. In the following I describe the sources of the data that is used in the quantification.

\section{A.1 Aggregate value of bilateral trade}

I use the COMTRADE trade data of the year 2003 as provided by CEPII (Gaulier, Zignago, Sondjo, Sissoko, and Paillacar, 2010). This data set provides the dollar values of the bilateral trade flows between 239 economic entities (mostly countries) on the HS6 level of aggregation $X_{n i}(j)$, which corresponds to 5111 goods categories. Summing over all HS6 categories I get the aggregate value of a bilateral trade flow from exporting country $i$ to the importing country $n, X_{n i}=\sum_{j=1}^{5111} X_{n i}(j)$.

\section{A.2 Extensive margin of bilateral trade}

A simple and intuitive measure for the extensive margin is to count the number of HS6 categories with positive volumes

$$
m_{n i}=\sum_{j} I\left(X_{n i}(j)>0\right),
$$

where $I\left(X_{n i}(j)>0\right)$ is an indicator function taking the value of one if the bilateral trade flow from $i$ to $n$ in the HS6-category $j$ is positive. A potential drawback of this measure is the fact that the HS6-categories are defined for custom purposes, which is why heavily regulated goods tend to have more categories. The associated measurement error is absorbed into the error term and the estimated elasticities are unbiased if the coarseness of the traded HS6-categories is orthogonal to the regressors.

An alternative measure for the extensive margin is brought forward by Broda and Weinstein (2006)

$$
m_{n i}^{B W}=\frac{\sum_{j} X_{n}(j) I\left(X_{n i}(j)>0\right)}{\sum_{j} X_{n}(j)}
$$

where $X_{n}(j)=\sum_{k \neq n, i} X_{n k}(j)$ is the value of country $n$ 's total imports in category $j$. There are two reasons why this measure may be inappropriate in my context. First, this measure is derived using a CES-demand system (Feenstra, 1994), whereas the central assumption in my model is that preferences are non-CES. Second, it has been argued that besides being directly derived from an underlying preference structure the advantage of this measure is that the categories are weighted 
which may alleviate measurement errors due to differences in the coarseness of the categorization. In the context of my model, the numerator then would represent the extensive margin of bilateral trade, $m_{n i}$, and the denominator is the multilateral extensive margin of imports, i.e. the measure of varieties that are sourced internationally, $\sum_{k \neq n} m_{n k}$. Using the corresponding expressions from the model one sees that the central element of my theory - the extensive margin of consumption - cancels, $m_{n i} / \sum_{k \neq n} m_{n k}=\pi_{n i} /\left(1-\pi_{n n}\right)$. In other words the Broda and Weinstein (2006)-measure is unlikely to reflect the income effects coming from the non-homothetic consumer behavior.

\section{A.3 Per-capita incomes and population sizes}

The per-capita incomes and the population sizes are taken from the Worldbank's World Development Indicator. The per-capita incomes are measured in current (year 2003) US-dollars. Following EK I deliberately abstain from using purchasing power adjusted incomes as deviations from PPP arise endogenously in the EK framework.

\section{A.4 Bilateral distances, shared border, and common language}

All transportation cost proxies are from the database provided by CEPII. The bilateral distance is measured as the distance between two countries' most populous cities. The common language indicator takes the value one if two countries have the same official language ${ }^{30}$ and common border takes the value one if two countries share a common land-border.

\section{A.5 CEX}

The US consumer expenditure survey (CEX) is a rotating panel collected by the Bureau of Labor Statistics (BLS). Its "interview survey" part provides detailed information on household characteristics and expenditures. One of the main purpose of the survey its use in determining and revising the baskets that are used for the computation of the consumer price index. I obtain the CEX data from the website of the Inter-University Consortium for Political and Social Research (ICPSR). A detailed documentation of the data can be found in BLS (2003). In the following I briefly discuss the raw data and how I processed the raw data.

The unit of observation in the CEX is a "consumer unit", CU, which basically comprises of all

\footnotetext{
${ }^{30}$ The results remain basically unchanged when using major languages instead of official languages.
} 
members of a household using their income to make joint expenditures. ${ }^{31}$ Each $\mathrm{CU}$ is in the panel for 5 consecutive quarters with one interview per quarter. The initial interview only collects demographic characteristics, whereas the following four interviews collect expenditures from the previous three months. Expenditures are collected for around 600 categories (represented by "universal classification codes", UCC). Of these 600 UCCs I select the UCCs that correspond to tradable manufactures. This clearly involves some ad-hoc decisions. I develop two classifications - a conservative classification, where I disregard all uncertain UCCs and a liberal classification, which includes more UCCs. Particularly difficult are housing related items since they are often separated by renter, owned home, and owned vacation home. For the conservative classification I disregard these UCCs all together. In the liberal classification I lump together the renter and owner categories for the same expense, e.g. I combine the categories "Installed and non-installed replacement wall to wall carpeting for owned homes" and "Installed and non-installed original wall to wall carpeting for rental homes" into one category, and ignore UCCs that are only available for either renter or owner such as "Installed and non-installed original wall to wall carpeting for owned homes". Another difficult class of UCCs is related to cloths - a CU buying "men's footwear" depends very much on if this CU comprises an adult male. Therefore, in the liberal classification, I lump together UCCs across gender and age, e.g. I collapse "men's footwear", "women's footwear", "Boys' footwear", and "Girls' footwear" into one category. The conservative classification disregards these categories. In the end, the liberal classification consists of 186 distinct expenditure categories, whereas the conservative classification comprises of 107 categories.

\section{A.6 Manufacturing absorption}

I use data from the United Nations Industrial Development Organization (UNIDO, 2003) on gross manufacturing output. For the year 2003 this database provides the gross manufacturing output for 74 countries. Unfortunately, the database does not include gross output for several large countries, most notably China. I therefore choose to impute the gross manufacturing output for countries that belong to the 20 largest economies in 2003 and for which I do not observe gross manufacturing output. I do this by following Eaton, Kortum, and Kramarz (2004) and scaling value added in the manufacturing sector by the average ratio of gross output and value added across countries. These countries are China, Switzerland, Canada, and Mexico.

\footnotetext{
${ }^{31}$ Under this definition a family constitutes a CU, whereas a roomer living with a family would constitute his own CU as he is financially independent.
} 


\section{A.7 Top quintiles of income distributions}

I get data on the top quintiles of the income distributions from UNU-WIDER (2008). A well-known problem of inequality data is that the measure to which the inequality data refer varies across countries. In particular some quintiles refer to expenditures and others to income. Moreover income may be measured in gross or net terms. To correct for this I follow Dollar and Kraay (2002) and regress the observed quintiles on dummies for the underlying measure. I then use the resulting coefficients to estimate the net income quintiles.

\section{B Some derivations}

\section{B.1 Derivation of the country specific price distribution $G_{n}(p)$}

Using the productivity distribution and the pricing equation (4) the probability of country $i$ supplying a particular variety $j$ at a price lower than $p$ in market $n$ can be written as

$$
\begin{aligned}
& G_{n i}(p)=\operatorname{Pr}\left[P_{n i} \leq p\right]=\operatorname{Pr}\left[\frac{w_{i} d_{n i}}{Z_{i}(j)} \leq p\right]=\operatorname{Pr}\left[\frac{w_{i} d_{n i}}{p} \leq Z_{i}(j)\right] \\
&=1-\exp \left\{-T_{i}\left(w_{i} d_{n i}\right)^{-\theta} p^{\theta}\right\} .
\end{aligned}
$$

The probability that the lowest price on offer in market $n$ is below $p$ is the complement to the probability that all offered prices lie above $p$

$$
G_{n}(p)=\operatorname{Pr}\left[\min \left\{P_{n i}(j)\right\}_{i=1}^{N} \leq p\right]=1-\operatorname{Pr}\left[\min \left\{P_{n i}(j)\right\}_{i=1}^{N}>p\right]
$$

As the productivity draws are iid across countries above probability is simply the product of the individual probabilities, which yields the price distribution from the main text

$$
G_{n}(p)=1-\sum_{i=1}^{N} \operatorname{Pr}\left[P_{n i}(j)>p\right]=1-\exp \left\{-p^{\theta} \sum_{i=1}^{N} T_{i}\left(w_{i} d_{n i}\right)^{-\theta}\right\} .
$$

\section{B.2 Derivation of the trade share $\pi_{n i}$}

The probability that country $i$ is the cheapest supplier for a variety $j$ in market $n$ is given by

$$
\pi_{n i}(j)=\operatorname{Pr}\left[P_{n i}(j)<\min \left\{P_{n k}(j)\right\}_{k \neq i}\right]=\int_{0}^{\infty} \operatorname{Pr}\left[p<\min \left\{P_{n k}(j)\right\}_{k \neq i}\right] d G_{n i}(p) .
$$


Again one can write the distribution of the minimum price as the product of the individual distributions

$$
\begin{aligned}
& \int_{0}^{\infty} \operatorname{Pr}\left[p<\min \left\{P_{n k}(j)\right\}_{k \neq i}\right] d G_{n i}(p)=\int_{0}^{\infty} \prod_{k \neq i} \operatorname{Pr}\left[p<P_{n k}(j)\right] d G_{n i}(p) \\
&=\int_{0}^{\infty} \prod_{k \neq i} G_{n k}(p) d G_{n i}(p) .
\end{aligned}
$$

Inserting for the price distributions yields

$$
\pi_{n i}(j)=\int_{0}^{\infty} \prod_{k \neq i} G_{n k}(p) d G_{n i}(p)=\frac{T_{i}\left(w_{i} d_{n i}\right)^{-\theta}}{\sum_{k=1}^{N} T_{k}\left(w_{k} d_{n k}\right)^{-\theta}}
$$

Note that this probability does not depend on the index $j$ so that it also represents the shares of varieties for which country $i$ is the cheapest supplier in $n$

$$
\pi_{n i}(j)=\pi_{n i}=\frac{T_{i}\left(w_{i} d_{n i}\right)^{-\theta}}{\Phi_{n}}
$$

\section{B.3 Conditional on entry price distributions are the same across sources}

The distribution of prices from country $i$ in market $n$ conditional on being the cheapest supplier is

$$
\operatorname{Pr}\left[P_{n i}(j) \leq p \mid P_{n i}(j)<\min \left\{P_{n k}(j)\right\}_{k \neq i}\right]=\frac{\operatorname{Pr}\left[P_{n i}(j) \leq p, P_{n i}(j)<\min \left\{P_{n k}(j)\right\}_{k \neq i}\right]}{\operatorname{Pr}\left[P_{n i}(j)<\min \left\{P_{n k}(j)\right\}_{k \neq i}\right]}
$$

The denominator is $\pi_{n i}$. The nominator can be written as

$$
\operatorname{Pr}\left[P_{n i}(j) \leq p, P_{n i}(j)<\min \left\{P_{n k}(j)\right\}_{k \neq i}\right]=\int_{0}^{p} \operatorname{Pr}\left[P_{n i}(j)<\min \left\{P_{n k}(j)\right\}_{k \neq i}\right] d G_{n i}(p)
$$

Similar steps as above yield

$$
\operatorname{Pr}\left[P_{n i}(j) \leq p, P_{n i}(j)<\min \left\{P_{n k}(j)\right\}_{k \neq i}\right]=\pi_{n i} G_{n}(p)
$$

Reinserting this into the initial expression completes the proof

$$
\operatorname{Pr}\left[P_{n i}(j) \leq p \mid P_{n i}(j)<\min \left\{P_{n k}(j)\right\}_{k \neq i}\right]=G_{n}(p)=\operatorname{Pr}\left[\min \left\{P_{n k}(j)\right\}_{i=1}^{N} \leq p\right] .
$$




\section{B.4 Derivation of the budget constraint for Stone-Geary preferences}

First note that with Stone-Geary utility the first order conditions (1) become

$$
\begin{aligned}
\frac{1}{x(j)+\bar{x}}=\lambda p(j) & \text { for } x(j)>0 \\
\frac{1}{\bar{x}}<\lambda p(j) & \text { for } x(j)=0 .
\end{aligned}
$$

Using these first order conditions I can solve for the price of the marginal variety

$$
p(M)=\frac{v^{\prime}(0)}{\lambda}=\frac{1}{\bar{x} \lambda}
$$

and for the inverse of the marginal utility of income respectively

$$
\frac{1}{\lambda}=\bar{x} p(M)
$$

Optimal expenditures for varieties $j<M$ are

$$
p(j) x(j)=\frac{1}{\lambda}-\bar{x} p(j)=\bar{x}(p(M)-p(j)) .
$$

Inserting this into a country $n$ agent's budget restriction (3) yields

$$
w_{n}=\bar{x}\left(p\left(M_{n}\right) M_{n}-\int_{0}^{p(M)} p d G_{n}(p)\right)
$$

Using the country specific price distribution $G_{n}(p)$ one can write

$$
p\left(M_{n}\right)=G_{n}^{-1}\left(M_{n}\right)=\left(-\frac{\log \left(1-M_{n}\right)}{\Phi_{n}}\right)^{\frac{1}{\theta}}
$$

and

$$
d G_{n}(p)=\theta p^{\theta-1} \Phi_{n} \exp \left\{-p^{\theta} \Phi_{n}\right\} d p
$$

Substituting this into the budget contraint yields

$$
w_{n}=\bar{x}\left(\left(-\frac{\log \left(1-M_{n}\right)}{\Phi_{n}}\right)^{\frac{1}{\theta}} M_{n}-\int_{0}^{p(M)} p \theta p^{\theta-1} \Phi_{n} \exp \left\{-p^{\theta} \Phi_{n}\right\} d p\right) .
$$


Changing variables in the integral, $t=p^{\theta} \Phi_{n}$,

$$
w_{n}=\bar{x}\left(\left(-\frac{\log \left(1-M_{n}\right)}{\Phi_{n}}\right)^{\frac{1}{\theta}} M_{n}-\int_{0}^{p\left(M_{n}\right)^{\theta} \Phi_{n}}\left(\frac{t}{\Phi_{n}}\right)^{\frac{1}{\theta}} \exp \{-t\} d t\right)
$$

where the integral equals the incomplete Gamma function so that we can write

$$
w_{n}=\bar{x}\left(\left(-\frac{\log \left(1-M_{n}\right)}{\Phi_{n}}\right)^{\frac{1}{\theta}} M_{n}-\left(\frac{1}{\Phi_{n}}\right)^{\frac{1}{\theta}} \gamma\left(\frac{1}{\theta}+1, p\left(M_{n}\right)^{\theta} \Phi_{n}\right)\right) .
$$

Substituting for the price of the marginal variety and rearranging leads finally to the expression of the main text.

\section{B.5 Deriving the budget constraint for alternative utility functions}

In the following I derive analogs to equation (10) for quadratic and CARA preferences. The resulting equations pin down the extensive margin of consumption for a given income, $E$, and price distribution, $G(p)=1-\exp \left\{-\Phi p^{\theta}\right\}$.

\section{B.5.1 Quadratic utility}

With quadratic utility we have

$$
v^{\prime}(x)=1-a^{q u a d r} x
$$

So that optimal expenditures are

$$
p x=\left(a^{q u a d r} p-\lambda p^{2}\right) .
$$

Inserting this and the country specific price distribution into the budget constraint yields

$$
E=\left(a^{q u a d r} \int_{0}^{p(M)} p \Phi \theta p^{\theta-1} \exp \left\{-\Phi p^{\theta}\right\} d p-\lambda \int_{0}^{p(M)} p^{2} \Phi \theta p^{\theta-1} \exp \left\{-\Phi p^{\theta}\right\} d p\right)
$$

Changing variables, $t=\Phi p^{\theta}$, we get

$$
E=\left(a^{q u a d r} \int_{0}^{p(M)}\left(\frac{t}{\Phi}\right)^{\frac{1}{\theta}} \exp \{-t\} d t-\lambda \int_{0}^{p(M)}\left(\frac{t}{\Phi}\right)^{\frac{2}{\theta}} \exp \{-t\} d t\right)
$$


Using the first order condition for the extensive margin of consumption, $a^{\text {quadr }}=\lambda p(M)$, I can substitute for $\lambda$

$$
E=a^{q u a d r}\left(\int_{0}^{\Phi p(M)^{\theta}}\left(\frac{t}{\Phi}\right)^{\frac{1}{\theta}} \exp \{-t\} d t-\frac{1}{p(M)} \int_{0}^{\Phi p(M)^{\theta}}\left(\frac{t}{\Phi}\right)^{\frac{2}{\theta}} \exp \{-t\} d t\right)
$$

The integrals are incomplete Gamma functions

$$
E=a^{q u a d r}\left((\Phi)^{-\frac{1}{\theta}} \gamma\left(\frac{1}{\theta}+1 ; \Phi p(M)^{\theta}\right)-\frac{1}{p(M)}(\Phi)^{-\frac{2}{\theta}} \gamma\left(\frac{2}{\theta}+1 ; \Phi p(M)^{\theta}\right)\right)
$$

From the price distribution we have $\Phi p(M)^{\theta}=-\log (1-M)$ and $p(M)=$ $(-\log (1-M) / \Phi)^{-1 / \theta}$, so that

$$
\begin{aligned}
E=a^{q u a d r}(\Phi)^{-\frac{1}{\theta}} \gamma\left(\frac{1}{\theta}+1 ;-\log (1-M)\right) & \\
& -a^{q u a d r}(\Phi)^{-\frac{1}{\theta}}(-\log (1-M))^{-\frac{1}{\theta}} \gamma\left(\frac{2}{\theta}+1 ;-\log (1-M)\right) .
\end{aligned}
$$

\section{B.6 CARA}

With CARA we have

$$
v^{\prime}(x)=a^{c a r a} \exp \left(-a^{c a r a} x\right)
$$

Optimal expenditures are

$$
p x=-\frac{p}{a^{\text {cara }}} \log \left(\frac{\lambda p}{a^{\text {cara }}}\right) .
$$

As the price of the marginal variety is $p(M)=a^{\text {cara }} / \lambda$ we can write

$$
p x=-\frac{p}{a^{\text {cara }}} \log \left(\frac{p}{p(M)}\right)
$$

Inserting this into the budget constraint

$$
E=-\frac{1}{a^{\text {cara }}} \int_{0}^{p(M)} p \log \left(\frac{p}{p(M)}\right) d G(p)
$$


and substituting for $p(M)$ and $d G(p)$ we get

$$
E=-\frac{\theta \Phi}{a^{\text {cara }}} \int_{0}^{(-\log (1-M) / \Phi)^{\frac{1}{\theta}}} \log \left(\left(-\frac{\log (1-M)}{\Phi}\right)^{-\frac{1}{\theta}} p\right) p^{\theta} \exp \left(-\Phi p^{\theta}\right) d p
$$


Table 1: Dependent variable - extensive margin of bilateral trade

$\begin{array}{llr} & \text { variable } & \text { coefficient } \\ \text { per-capita income } & \text { exporter } & 0.66^{* * *} \\ & \text { importer } & 0.47^{* * *} \\ \text { population size } & \text { exporter } & 0.65^{* * *} \\ & \text { importer } & 0.30^{* * *} \\ \text { bilateral distance } & {[375,750)} & -0.78^{* * *} \\ & {[750,1500)} & -1.49^{* * *} \\ & {[1500,3000)} & -2.26^{* * *} \\ & {[3000,6000)} & -2.50^{* * *} \\ & {[6000, \infty)} & -2.88^{* * *} \\ \text { additional controls } & \text { shared border } & 0.45^{* * *} \\ & \text { same language } & 0.74^{* * *} \\ N=16053, R^{2}=0.63, & \\ & & \\ & & \end{array}$




\section{Table 2: Dependent variable - extensive margin of consumption}

\begin{tabular}{llllllllll} 
specification & \multicolumn{2}{c}{ I } & \multicolumn{2}{c}{ II } & \multicolumn{2}{c}{ III } & \multicolumn{2}{c}{ IV } \\
classification & cons. & liberal & cons. & liberal & cons. & liberal & cons. & liberal \\
expenditures & $0.48^{* * *}$ & $0.52^{* * *}$ & $0.43^{* * *}$ & $0.48^{* * *}$ & $0.42^{* * *}$ & $0.46^{* * *}$ & $0.41^{* * *}$ & $0.46^{* * *}$ \\
age dummies & no & no & yes & yes & yes & yes & yes & yes \\
HH members & no & no & no & no & yes & yes & yes & yes \\
geography & no & no & no & no & no & no & yes & yes \\
N & 2981 & 2982 & 2981 & 2982 & 2846 & 2847 & 2846 & 2847 \\
$R^{2}$ & 0.33 & 0.39 & 0.35 & 0.42 & 0.36 & 0.43 & 0.38 & 0.44
\end{tabular}


Table 3: Estimated trade costs

variable
$[375,750)$
$[750,1500)$
$[1500,3000)$
$[3000,6000)$
$[6000, \infty)$
shared border
same language

OECD

non-OECD

all countries estimated coefficients

$\begin{array}{rr}\text { coefficient } & \text { \%-effect } \\ -0.53^{* * *} & 13 \% \\ -1.52^{* * *} & 40 \% \\ -1.97^{* * *} & 55 \% \\ -2.84^{* * *} & 88 \% \\ -3.33^{* * *} & 110 \% \\ 0.77^{* * *} & -16 \% \\ 0.82^{* * *} & -17 \%\end{array}$

estimated trade costs $\left(d_{n i}\right)$

mean

median

1.89

3.53

3.14 
Table 4: : Income elasticities of the extensive margin of bilateral trade

\begin{tabular}{lllll} 
& \multicolumn{2}{c}{ elasticities in data } & \multicolumn{2}{c}{ elasticities in models } \\
& all vars & C only & non-homothetic & homothetic \\
exporter income & 0.83 & 0.65 & 0.86 & 0.86 \\
importer income & 0.49 & 0.46 & 0.63 & -0.12
\end{tabular}


Table 5: : Summary statistics for changes in trade costs

\begin{tabular}{lcccccc} 
& \multicolumn{2}{c}{$10 \%$-reduction } & \multicolumn{2}{c}{$25 \%$-reduction } & \multicolumn{2}{c}{$50 \%$-reduction } \\
& new & EK & new & EK & new & EK \\
mean & $9 \%$ & $2 \%$ & $27 \%$ & $5 \%$ & $103 \%$ & $37 \%$ \\
median & $8 \%$ & $0.1 \%$ & $22 \%$ & $-1 \%$ & $85 \%$ & $18 \%$ \\
top10\% & $22 \%$ & $16 \%$ & $65 \%$ & $43 \%$ & $207 \%$ & $118 \%$ \\
bottom10\% & $-2 \%$ & $-11 \%$ & $-3 \%$ & $-25 \%$ & $16 \%$ & $-31 \%$ \\
\% negative & $15 \%$ & $49 \%$ & $15 \%$ & $51 \%$ & $6 \%$ & $35 \%$
\end{tabular}


Table 6: List of countries in sample

\begin{tabular}{|c|c|c|c|}
\hline Afghanistan & Czech Republic & Kuwait & Sao Tome and Principe \\
\hline Albania & Denmark & Kyrgyzstan & Saudi Arabia \\
\hline Algeria & Dominica & Lao PDR & Senegal \\
\hline Angola & Dominican Republic & Latvia & Seychelles \\
\hline Antigua and Barbuda & Ecuador & Lebanon & Sierra Leone \\
\hline Argentina & Egypt & Libya & Singapore and Malaysia \\
\hline Armenia & El Salvador & Lithuania & Slovakia \\
\hline Australia & Equatorial Guinea & Macau & Slovenia \\
\hline Austria & Eritrea & Macedonia & Solomon Islands \\
\hline Azerbaijan & Estonia & Madagascar & South Africa \\
\hline Bahamas & Ethiopia & Malawi & Spain \\
\hline Bangladesh & Fiji & Mali & Sri Lanka \\
\hline Barbados & Finland & Malta & St. Kitts and Nevis \\
\hline Belarus & France & Mauritania & St. Lucia \\
\hline Belgium and Luxembourg & Gabon & Mauritius & Sudan \\
\hline Belize & Georgia & Mexico & Suriname \\
\hline Benin & Germany & Moldova & Sweden \\
\hline Bhutan & Ghana & Mongolia & Switzerland \\
\hline Bolivia & Greece & Morocco & Syria \\
\hline Bosnia and Herzegovina & Grenada & Mozambique & Tajikistan \\
\hline Brazil & Guatemala & Nepal & Tanzania \\
\hline Brunei Darussalam & Guinea & Netherlands & Thailand \\
\hline Bulgaria & Guinea-Bissau & New Zealand & Togo \\
\hline Burkina Faso & Guyana & Nicaragua & Tonga \\
\hline Burundi & Honduras & Niger & Trinidad and Tobago \\
\hline Cambodia & Hungary & Nigeria & Tunisia \\
\hline Cameroon & Iceland & Norway & Turkey \\
\hline Canada & India & Oman & Turkmenistan \\
\hline Cape Verde & Indonesia & Pakistan & Uganda \\
\hline Central African Republic & Iran & Palau & Ukraine \\
\hline Chad & Iraq & Papua New Guinea & United Arab Emirates \\
\hline Chile & Ireland & Paraguay & United Kingdom \\
\hline China and Hong Kong & Israel & Peru & United States of America \\
\hline Colombia & Italy & Philippines & Uruguay \\
\hline Comoros & Jamaica & Poland & Uzbekistan \\
\hline Congo, Dem. Rep. & Japan & Portugal & Vanuatu \\
\hline Congo, Rep. & Jordan & Qatar & Venezuela \\
\hline Costa Rica & Kazakhstan & Romania & Vietnam \\
\hline Cote d'Ivoire & Kenya & Russia & Yemen \\
\hline Croatia & Kiribati & Rwanda & Zambia \\
\hline Cyprus & Korea, Republic of & Samoa & Zimbabwe \\
\hline
\end{tabular}


Figure 1: Demand function

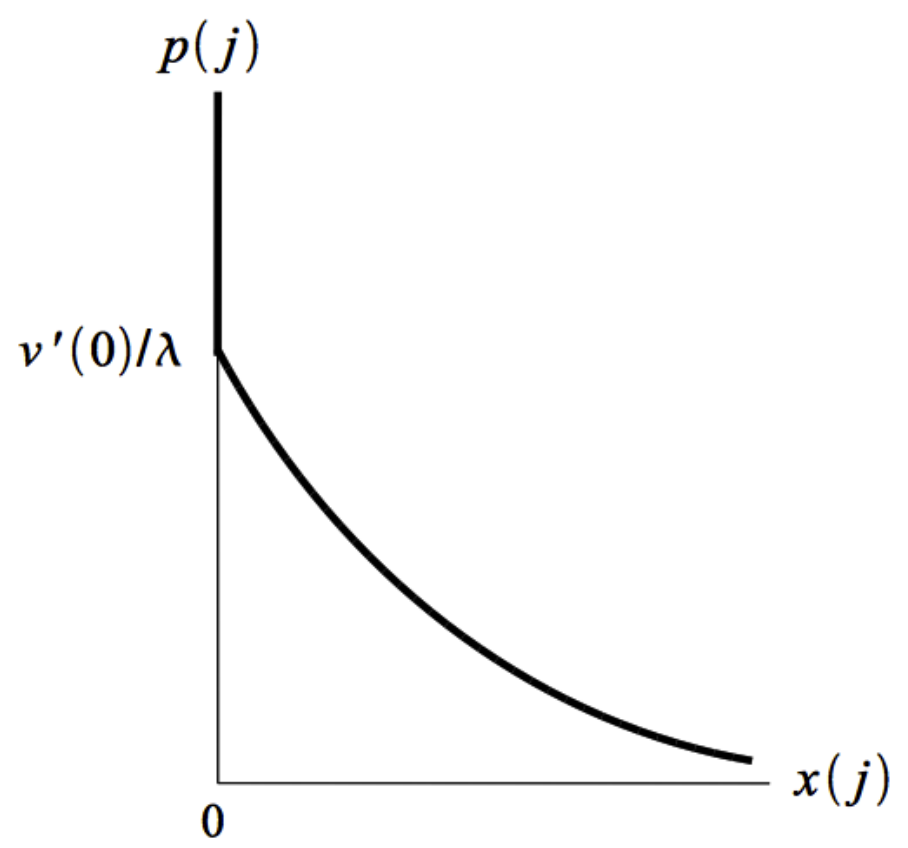


Figure 2: Extensive margin of consumption

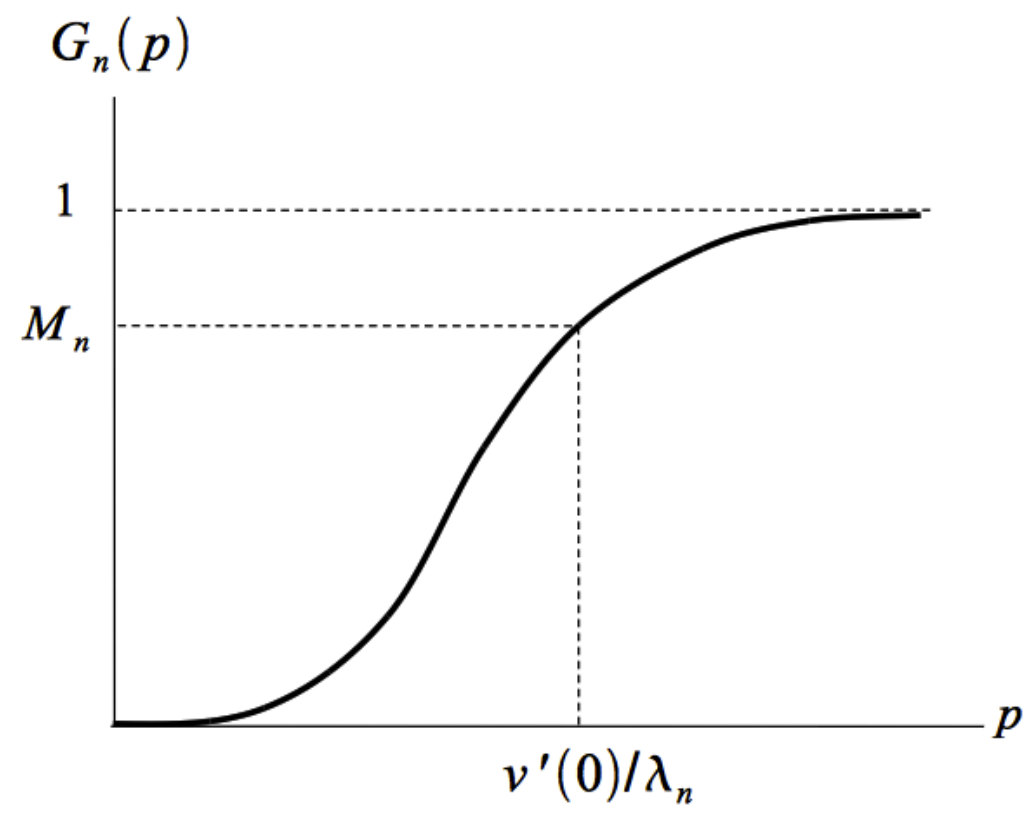


Figure 3: Calibrated technologies vs. observed incomes

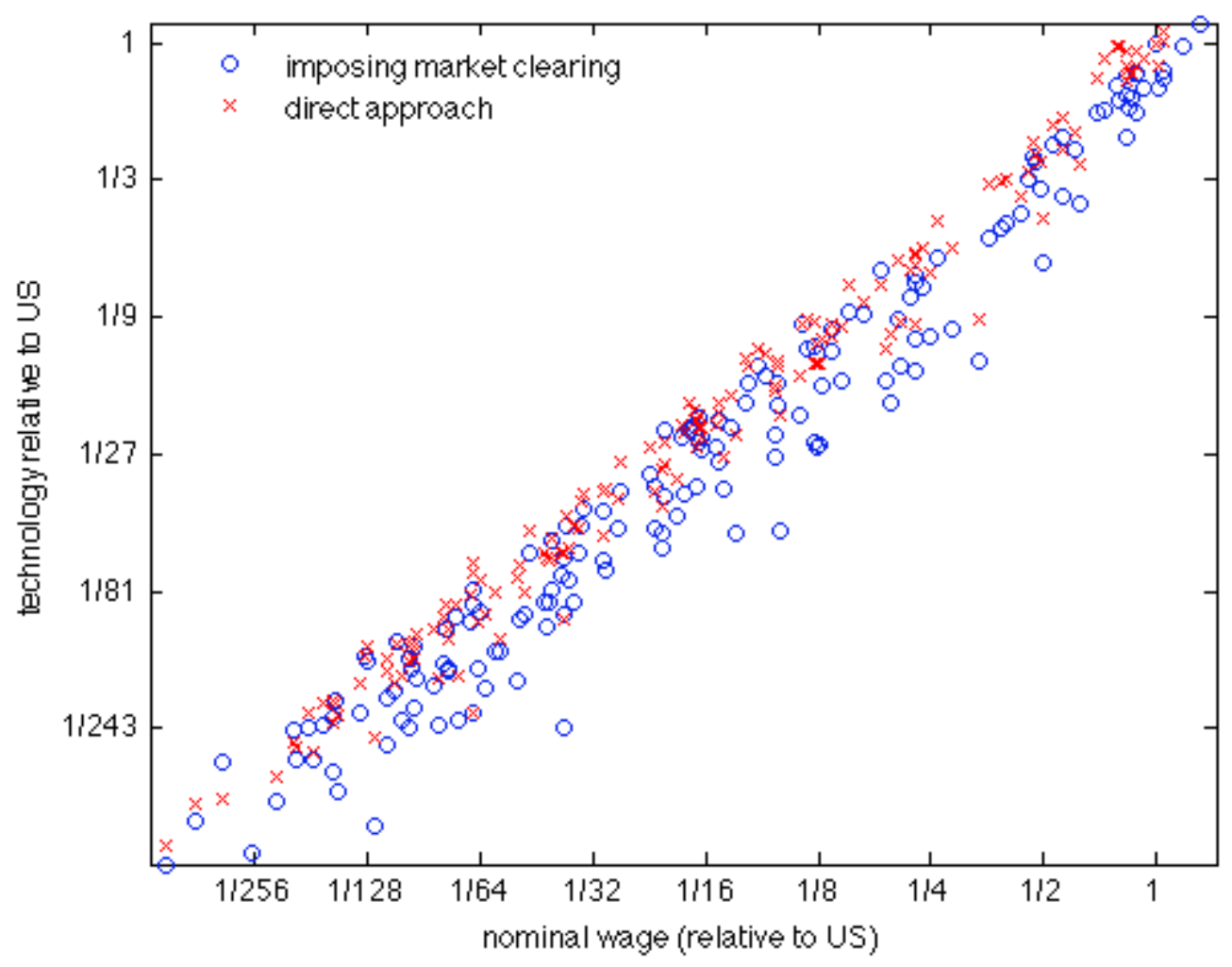


Figure 4: Calibrated extensive margins of consumption vs. observed incomes

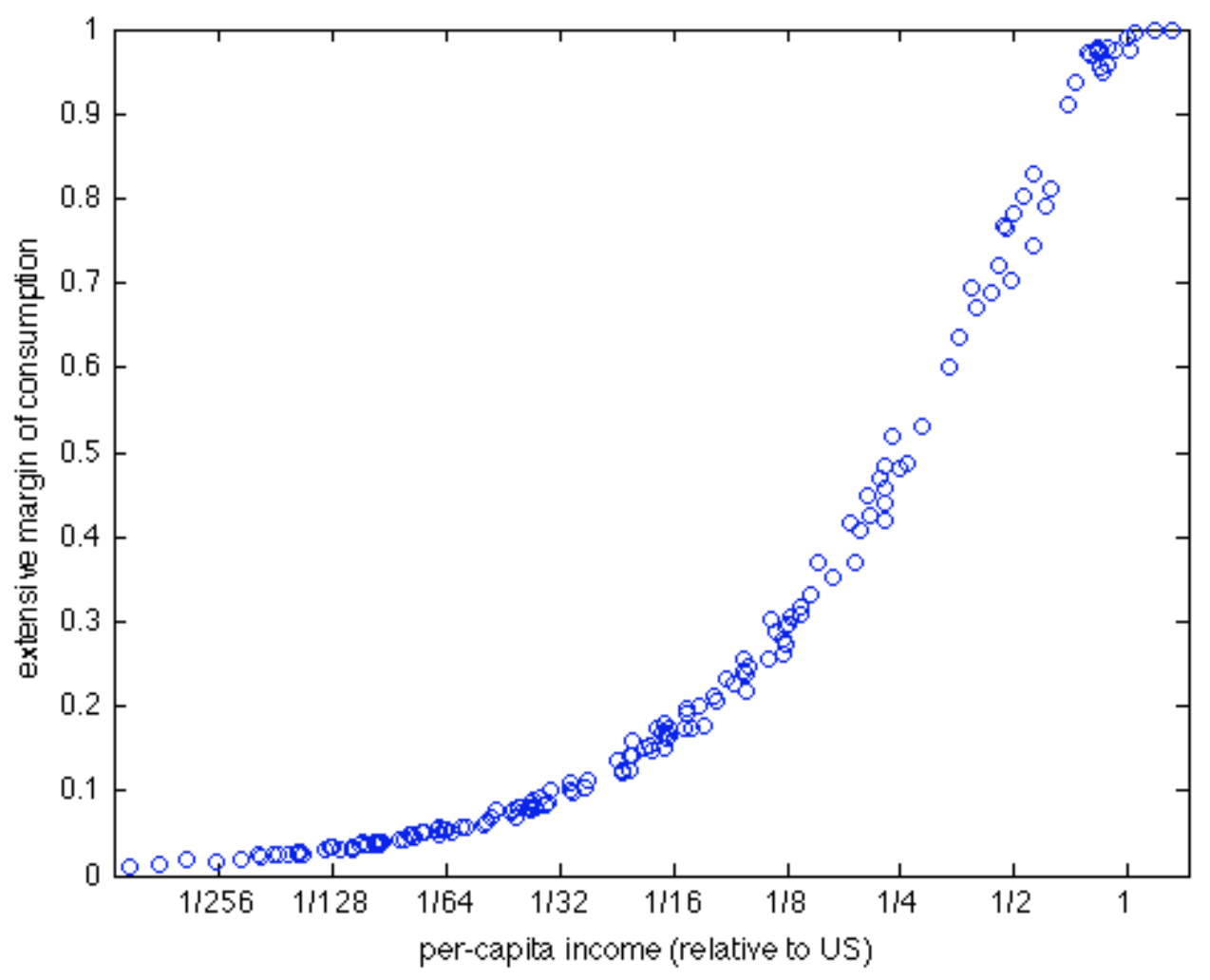


Figure 5: Absolute and relative changes in the extensive margin of consumption
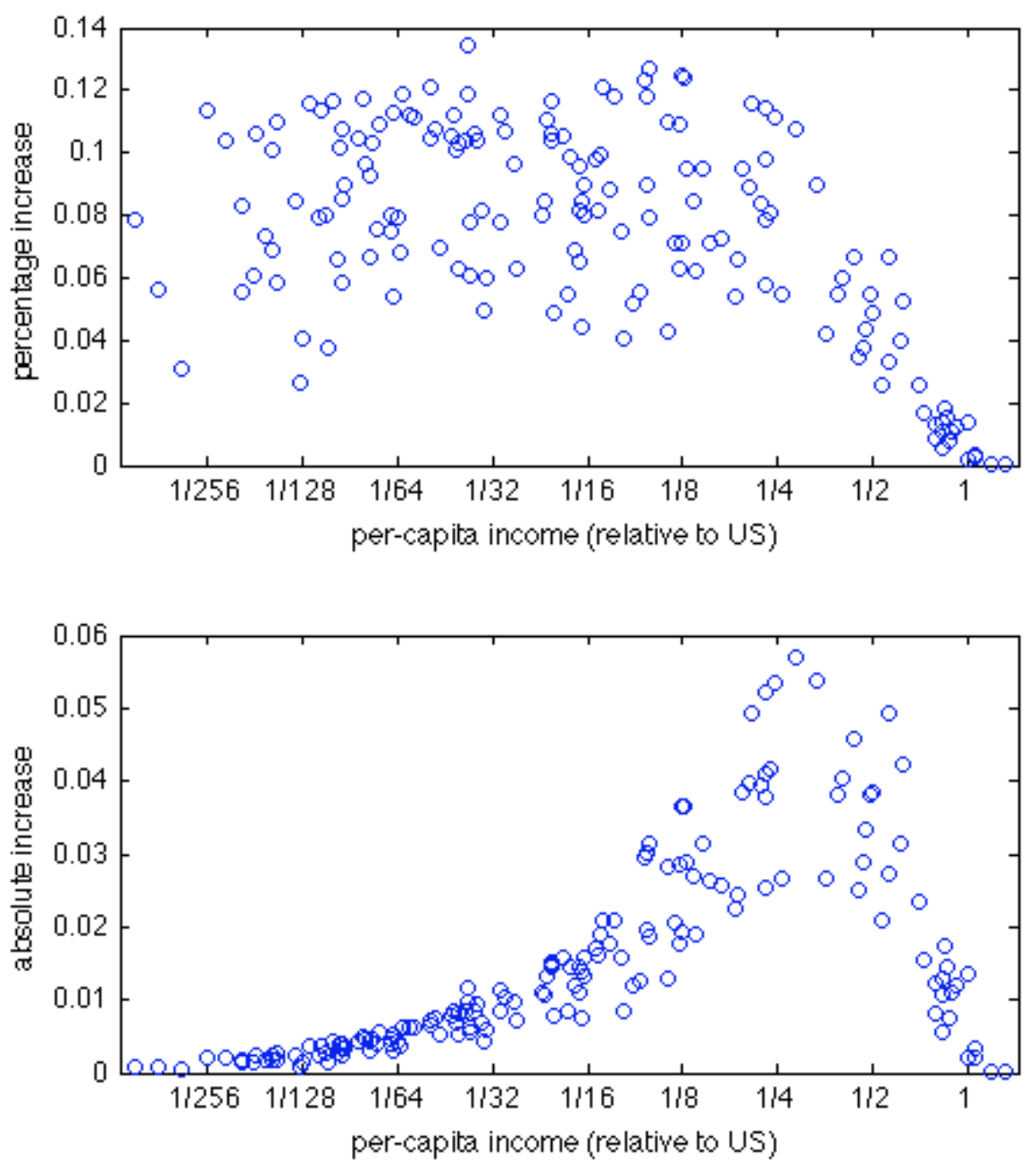